\title{
Muscle strength, endurance, and aerobic capacity in rheumatoid arthritis: a comparative study with healthy subjects
}

\author{
Charlotte Ekdahl, Gabriella Broman
}

\begin{abstract}
Isometric/isokinetic muscle strength and isokinetic endurance of the lower extremities as well as aerobic capacity were evaluated in 67 patients (43 female, 24 male; mean age 53 years, range 23-65) with classical/definite rheumatoid arthritis (RA) of functional class II. Results obtained were compared with those of a healthy reference group matched for age and sex.
\end{abstract}

Disease characteristics of the group with RA were registered and lifestyle characteristics, such as work load, exercise, diet, smoking, and alcohol habits, were reported by both groups. Generally, results showed that the group with RA had decreased functional capacity. Isometric hip and knee muscle strength of the rheumatoid group was reduced to about $75 \%$ of normal function, isokinetic knee muscle strength at the velocities of $\mathbf{6 0}$ and 180 degrees/s to about $65 \%$ and $75 \%$ of normal function respectively, isokinetic endurance of the knee muscle groups to about $45 \%$, and aerobic capacity to about $80 \%$ of the results obtained for the healthy reference group.

Analyses of variance showed that the rheumatoid group, compared with the healthy group, had significantly reduced function on all isometric and isokinetic tests of the extensors and flexors of the knee. Results for isometric hip muscle strength were similarall tests but one yielding highly significant differences. To avoid unnecessary functional deficits it seems important to include muscular training in rehabilitation programmes for patients with RA.

Impaired muscle function is a common consequence in patients with rheumatoid arthritis (RA). Results of a previous study indicated that about $80 \%$ of patients with large joints of the lower extremities affected by RA had problems related to muscle strength, endurance, and balance/coordination. ${ }^{\prime}$

Earlier studies have reported that patients with RA, as compared with healthy subjects, have reduced isometric ${ }^{2-6}$ and isokinetic ${ }^{2-7}$ muscle strength. Also, decreased isometric (static) muscular endurance has been reported for patients with RA as compared with healthy subjects. ${ }^{4}$ In another study ${ }^{6}$ which considered isokinetic (dynamic) endurance, however, no significant difference was found between patients with RA and healthy controls.

It has earlier been reported that patients with RA show lower cardiorespiratory fitness than normal subjects. ${ }^{2}$ In another study, however, no significant difference in maximal oxygen consumption was found between patients with RA and healthy, very sedentary, matched controls. ${ }^{6}$ The latter study concluded that both rheumatoid and control groups had reduced aerobic capacity.

Our study aimed at comparing the levels of isometric (hip, knee) and isokinetic (knee) muscle strength, isokinetic endurance of the knee muscle groups, and aerobic capacity in patients with RA and in healthy controls matched for age and sex. Also, an attempt was made to investigate how the selected variables of muscle function were related to disease activity of the patients with RA and lifestyle characteristics of both groups.

\section{Patients and methods} GROUP WITH RA

Sixty seven patients (43 female, 24 male; mean age 53.0 years (SD 10.2 ), range $23-65$ ) with classical/definite $\mathrm{RA}^{8}$ of functional class II $^{9}$ took part in the study. An epidemiological approach, further described elsewhere, ${ }^{10}$ was used to select the patients with RA. Table 1 gives characteristics of the patients, who all had low to moderate disease activity. Of the 67 patients with $R A, 11$ had been receiving no antirheumatic drugs, 16 were receiving simple analgesics or non-steroidal anti-inflammatory drugs or both, 31 were taking remission inducing drugs alone or together with corticosteroids in four cases, and five were receiving corticosteroids only.

\section{HEALTHY REFERENCE GROUP}

The patient group was compared with a group of 77 active, healthy controls (47 female, 30 male; mean age 51.0 (SD 10.4 ), range 24-65 years). The healthy subjects were, with a few exceptions, employed by the University Hospital in Lund and volunteered for the study.

The healthy reference group was matched with the rheumatoid group according to age and sex, but an additional 10 healthy subjects were included. These were evenly distributed according to age and sex and were included owing to the planning of a future follow up study. Of the 77 healthy subjects, four were receiving treatment with $\beta$ blockers (table 1).

\section{MEASUREMENTS}

\section{Isometric muscle strength}

Isometric muscle strength of the extensors, flexors, abductors, and adductors of the hip was measured in a lying position by a strain gauge 
Table 1 Characteristics of the rheumatoid and healthy control groups

\begin{tabular}{|c|c|c|c|c|c|c|}
\hline \multirow[t]{2}{*}{ Characteristic } & \multicolumn{3}{|l|}{ Patients with $R A^{*}$} & \multicolumn{3}{|c|}{ Controls } \\
\hline & Mean & $S D$ & Range & Mean & $S D$ & Range \\
\hline \multirow{14}{*}{$\begin{array}{l}\text { Age (years) } \\
\text { Height (cm) } \\
\text { Women } \\
\text { Men } \\
\text { Weight (kg) } \\
\text { Women } \\
\text { Men } \\
\text { Duration of disease (years) } \\
\text { ESR }^{*}(\mathrm{~mm} / \mathrm{h}) \\
\text { CRP* (g/l) } \\
\text { Morning stiffness (min) } \\
\text { HAQ } \text { disability index }^{*} \\
\text { Pain (VAS*) } \\
\text { Ritchie articular index } \\
\text { Index of joint mobility (\%) } \\
\text { MF* index }^{*}\end{array}$} & $53 \cdot 0$ & $10 \cdot 2$ & $23-65$ & $51 \cdot 0$ & $10 \cdot 4$ & $24-65$ \\
\hline & $\begin{array}{l}164 \cdot 1 \\
177 \cdot 9\end{array}$ & $\begin{array}{l}5 \cdot 6 \\
6 \cdot 8\end{array}$ & $\begin{array}{l}152-176 \\
164-195\end{array}$ & $\begin{array}{l}165 \cdot 1 \\
177 \cdot 3\end{array}$ & $\begin{array}{l}5 \cdot 3 \\
8 \cdot 1\end{array}$ & $\begin{array}{l}151-178 \\
153-193\end{array}$ \\
\hline & & & & & & \\
\hline & $66 \cdot 1$ & $11 \cdot 6$ & $44-106$ & $62 \cdot 7$ & $9 \cdot 4$ & $50-95$ \\
\hline & $75 \cdot 6$ & $\begin{array}{r}10 \cdot 7 \\
7.0\end{array}$ & $56-110$ & $74 \cdot 6$ & $9 \cdot 9$ & $62-95$ \\
\hline & $\begin{array}{l}10.6 \\
25.0\end{array}$ & $\begin{array}{r}7 \cdot 8 \\
19 \cdot 0\end{array}$ & $\begin{array}{l}1-37 \\
3-125\end{array}$ & - & - & - \\
\hline & $23 \cdot 5$ & $28 \cdot 0$ & $12-137$ & - & - & - \\
\hline & $56 \cdot 1$ & $57 \cdot 4$ & $0-260$ & - & - & - \\
\hline & 0.9 & 0.6 & $0-2 \cdot 9$ & - & - & - \\
\hline & $1 \cdot 2$ & 0.8 & $0-3 \cdot 0$ & - & - & \\
\hline & $11 \cdot 5$ & $8 \cdot 2$ & $0-36$ & - & - & - \\
\hline & $92 \cdot 1$ & $7 \cdot 7$ & $65-100$ & - & - & - \\
\hline & $7 \cdot 7$ & $6 \cdot 5$ & $0-25$ & - & & - \\
\hline & & \multicolumn{2}{|c|}{ Number } & \multicolumn{2}{|c|}{ Number } & \\
\hline \multirow{10}{*}{\multicolumn{2}{|c|}{$\begin{array}{l}\text { Sex (female/male) } \\
\text { Waaler-Rose test (pos/neg) } \\
\text { Rheumatoid nodules (yes/no) } \\
\text { Major joint affected (hip/knee/ankle) } \\
\text { Work load (light/moderate/heavy) } \\
\text { Leisure activities (never/sometimes/regularly/intensive) } \\
\text { Diet (ordinary/lactoveg/veg) } \\
\text { Smoking (0/1-5/6-10/>10 cig) } \\
\text { Alcohol (never/seldom/regularly) } \\
\text { Drugs (yes/no) } \\
\text { Disability pension (full/partial/none) }\end{array}$}} & \multirow{10}{*}{\multicolumn{2}{|c|}{$\begin{array}{l}43 / 24 \\
44 / 23 \\
24 / 43 \\
16 / 16 / 35 \\
49 / 11 / 7 \\
12 / 13 / 42 / 0 \\
61 / 3 / 3 \\
49 / 7 / 3 / 8 \\
26 / 40 / 1 \\
56 / 11 \\
32 / 6 / 29\end{array}$}} & \multicolumn{2}{|c|}{$47 / 30$} & \\
\hline & & & & \multicolumn{2}{|c|}{ - } & \\
\hline & & & & - & & \\
\hline & & & & \multicolumn{2}{|c|}{-} & \\
\hline & & & & \multirow{2}{*}{\multicolumn{2}{|c|}{$\begin{array}{l}32 / 25 / 20 \\
2 / 12 / 50 / 13\end{array}$}} & \\
\hline & & & & & & \\
\hline & & & & \multirow{2}{*}{\multicolumn{2}{|c|}{$\begin{array}{l}70 / 1 / 6 \\
57 / 4 / 7 / 9\end{array}$}} & \\
\hline & & & & & & \\
\hline & & & & \multicolumn{2}{|c|}{$11 / 63 / 3$} & \\
\hline & & & & \multicolumn{2}{|c|}{$\begin{array}{l}4 / 73 \\
0 / 0 / 77\end{array}$} & \\
\hline
\end{tabular}

${ }^{*} \mathrm{RA}=$ rheumatoid arthritis; $\mathrm{ESR}=$ erythrocyte sedimentation rate; $\mathrm{CRP}=\mathrm{C}$ reactive protein; $\mathrm{HAQ}=$ modified Health Assessment Questionnaire ${ }^{15}$; VAS = visual analogue score; $M F=$ muscle function.

dynamometer attached to the ankle. Three measurements, each with a minimum duration of three seconds, were made in each direction, the highest value obtained being selected for statistical analysis.

Isometric muscle strength of the extensors and flexors of the knee was measured with a Cybex II isokinetic dynamometer ${ }^{11}$ connected to a personal computer, with the patient in a fixed sitting position (hip in 90 degrees and knee in 60 degrees of flexion), the hold duration being three seconds. The sampling frequency was $60 \mathrm{~Hz}$, a mean value being calculated for a two second period, beginning one second after start. The highest mean value obtained on three tests was used in statistical calculations. Torque due to the weight of the lower leg was corrected for by the computer. Vocal instructions for the tests were standardised.

\section{Isokinetic muscle strength and endurance}

Isokinetic muscle strength of the extensors and flexors of the knee was measured with a Cybex II isokinetic dynamometer (corrected for torque, see above) at velocities of 60 and 180 degrees/s, sampling frequencies being $120 \mathrm{~Hz}$ and $360 \mathrm{~Hz}$ respectively. Standardised vocal instructions were given. The patients performed three trials at 60 degrees/s and as many as they were able to (with a maximum of 40 ) at 180 degrees/s. The highest of the mean values obtained, sampled in the interval 75-25 degrees of flexion of the knee joint, was used in the further analyses.

Isokinetic endurance, defined here as maximum work capacity (sum of the mean values in newton metres of the contractions carried out), was measured for the extensors and flexors of the knee at 180 degrees $/ \mathrm{s}^{10}$

The patients were asked to rate their perceived exertion, as described by Borg, ${ }^{12}$ immediately after the muscle testing procedure.

\section{Aerobic capacity}

Åstrand's method ${ }^{13}$ was used to calculate the maximum oxygen uptake $\left(\mathrm{Vo}_{2} \max\right.$ in $\mathrm{ml} /$ kg.min) during a submaximal work load provided by a bicycle ergometer. Immediately after the testing the rate of perceived exertion was scored by the patient. Subjects receiving $\beta$ blockers were excluded from this test.

\section{Index of muscle function}

A battery of functional tests for muscle strength, endurance, and balance/coordination of the lower extremities ${ }^{1}$ was used (muscle function indices). A patient's performance on the various tests was assessed by an observer using a three point scale (0-2), the maximum scores on the three separate indices being $14,10,10$, respectively (muscle function index $=34$ ); a high score represented severe disability.

\section{Disease activity}

Estimated disease activity of the patients with RA was based on several measurements. Activities of daily living and pain intensity experienced during the past week were scored by the patients using a modified version ${ }^{14}$ of the Stanford Health Assessment Questionnairethe disability index. ${ }^{15}$ An index of joint mobility was calculated, based on measurement (with a goniometer) of range of motion for all large joints of the lower extremities-100\% representing normal joint mobility. ${ }^{14}$ Ritchie articular index was calculated, ${ }^{16}$ and erythrocyte sedimentation rate and $C$ reactive protein were determined. Patients' reports of morning stiffness were noted in minutes. 
structured interview. The variable of physical work load in daily living was based on a modified version of a test described by Meenan et $a l,{ }^{17}$ and included the following categories: $1=$ light physical work, mainly sitting; $2=$ moderately heavy physical work involving frequent movements; 3 =heavy physical work. The categories refer to the actual work load.

Inquiries about leisure activities, representing exercise habits (never/sometimes/regularly/ intensive), and disability pension (full/partial/ none) were made. In addition, lifestyle variables, such as diet, smoking, and alcohol consumption, were reported by all the subjects, who answered a structured questionnaire (table 1). Attitudes towards physical training were also scored by the patient on a 100 point truth value scale, ${ }^{18}$ 100 representing total agreement and 0 complete disagreement with the statement given. The following items were included: 'I think physical training is important for me' and 'I think physical training is fun'.

\section{STATISTICS}

Analyses of variance on differences between groups were carried out with the SAS statistical package. ${ }^{19}$ In addition, correlation analyses according to Spearman were performed. A significance level of $p=0.05$ was selected.

\section{Results}

No significant differences between the rheumatoid and the healthy group were found for age, sex, height, and weight (analysis of variance, $\chi^{2}$ test). Tables 2 and 3 show the means and standard deviations for isometric and isokinetic muscle strength, isokinetic endurance, aerobic capacity, index of muscle function, and rate of perceived exertion for the rheumatoid and the matched healthy controls grouped according to age and sex.

Results obtained indicated decreased function for the rheumatoid group compared with the healthy group for all the variables of isometric and isokinetic muscle strength, isokinetic endurance, aerobic capacity, and muscle function index.

Isometric hip (extensors, flexors, abductors, adductors) and knee (extensors, flexors) muscle strength of the rheumatoid patients was reduced to about $75 \%$ of normal function and isokinetic muscle strength of the knee extensors and flexors at 60 and 180 degrees/s to about $75 \%$ and $65 \%$ of normal function respectively.

The isokinetic endurance of the patients with RA was about $45 \%$ of normal. It was found that older rheumatoid men ( $>54$ years) showed least functional decrease (about $45 \%$ ) and younger rheumatoid men $(\leqslant 54$ years) most functional decrease (about $60 \%$ ) as compared with healthy controls in the corresponding age group. No such pattern was found for the rheumatoid women (about $45 \%$ decrease in both groups).

\section{COMPARISONS BETWEEN THE GROUP WITH RA AND THE HEALTHY GROUP \\ Isometric muscle strength}

Significant differences $(p<0.001)$ between the rheumatoid and healthy groups were found for isometric strength of the extensors and flexors of the knee, with the rheumatoid group showing decreased muscular function. Furthermore, significant differences according to age

Table 2 Means and standard deviations for the female patients with rheumatoid arthritis and healthy control women of the tests for isometric/isokinetic muscle strength, isokinetic endurance, aerobic capacity, and rate of perceived exertion

\begin{tabular}{|c|c|c|c|c|c|c|c|c|}
\hline \multirow[t]{2}{*}{ Test } & \multicolumn{4}{|c|}{ Women with $R A$} & \multicolumn{4}{|c|}{ Healthy control women } \\
\hline & $\begin{array}{l}(n=23) \\
\leqslant 54 \text { years } \\
\text { Mean }\end{array}$ & $S D$ & $\begin{array}{l}(n=20) \\
>54 \text { years } \\
\text { Mean }\end{array}$ & $S D$ & $\begin{array}{l}(n=30) \\
\leqslant 54 \text { years } \\
\text { Mean }\end{array}$ & $S D$ & $\begin{array}{l}(n=17) \\
>54 \text { years } \\
\text { Mean }\end{array}$ & $S D$ \\
\hline \multicolumn{9}{|l|}{ Isometric strength (Nm) } \\
\hline Knee ext ${ }^{*}$,right & $87 \cdot 8$ & $26 \cdot 6$ & $74 \cdot 2$ & $26 \cdot 1$ & $112 \cdot 8$ & $29 \cdot 3$ & 90.5 & $25 \cdot 3$ \\
\hline ext left & $96 \cdot 1$ & $26 \cdot 8$ & $76 \cdot 6$ & $26 \cdot 4$ & $119 \cdot 2$ & $32 \cdot 3$ & $96 \cdot 6$ & $26 \cdot 3$ \\
\hline $\begin{array}{l}\text { flex }{ }^{*} \text { right } \\
\text { flex left }\end{array}$ & $35 \cdot 3$ & $9 \cdot 4$ & $29 \cdot 8$ & $10 \cdot 2$ & $\begin{array}{l}54 \cdot 8 \\
50.7\end{array}$ & $\begin{array}{l}17 \cdot 1 \\
10 \cdot 1\end{array}$ & $\begin{array}{r}41 \cdot 0 \\
41 \cdot 8\end{array}$ & 11.8 \\
\hline $\begin{array}{l}\text { flex left } \\
\text { Hip ext right }(N)\end{array}$ & $\begin{array}{l}43 \cdot 7 \\
83 \cdot 1\end{array}$ & $\begin{array}{l}13 \cdot 9 \\
23 \cdot 3\end{array}$ & 34.5 & $12 \cdot 6$ & $\begin{array}{l}59 \cdot 7 \\
96.6\end{array}$ & $26 \cdot 3$ & $\begin{array}{l}43.8 \\
83.5\end{array}$ & $\begin{array}{l}11 \cdot 9 \\
23 \cdot 0\end{array}$ \\
\hline $\begin{array}{l}\text { Hip ext right }(N) \\
\text { ext left }\end{array}$ & 77.5 & 29.5 & $70 \cdot 8$ & 15.5 & 97.5 & $24 \cdot 4$ & 82.5 & 18.0 \\
\hline flex right & $58 \cdot 1$ & $15 \cdot 9$ & $48 \cdot 1$ & $13 \cdot 0$ & $61 \cdot 7$ & $17 \cdot 5$ & $54 \cdot 2$ & $19 \cdot 3$ \\
\hline flex left & $53 \cdot 0$ & $18 \cdot 4$ & $44 \cdot 3$ & $13 \cdot 1$ & $65 \cdot 6$ & $20 \cdot 1$ & $56 \cdot 1$ & $15 \cdot 9$ \\
\hline abd* right & $64 \cdot 2$ & $32 \cdot 5$ & $48 \cdot 0$ & $17 \cdot 7$ & $104 \cdot 9$ & $32 \cdot 8$ & $101 \cdot 6$ & $29 \cdot 6$ \\
\hline abd left & $63 \cdot 4$ & $24 \cdot 6$ & $45 \cdot 6$ & $20 \cdot 0$ & $119 \cdot 0$ & $36 \cdot 2$ & $99 \cdot 6$ & $22 \cdot 0$ \\
\hline $\operatorname{add}^{*}$ right & $109 \cdot 3$ & $36 \cdot 0$ & $83 \cdot 0$ & $22 \cdot 9$ & $128 \cdot 5$ & $49 \cdot 9$ & $95 \cdot 7$ & $33 \cdot 1$ \\
\hline add left & $103 \cdot 5$ & $37 \cdot 4$ & $78 \cdot 1$ & 23.9 & $129 \cdot 9$ & $40 \cdot 4$ & $107 \cdot 4$ & $42 \cdot 4$ \\
\hline \multicolumn{9}{|l|}{ Isokinetic strength $(\mathrm{Nm})$} \\
\hline Knee ext right $60^{\circ} / \mathrm{s}$ & $64 \cdot 4$ & $\begin{array}{l}18 \cdot 0 \\
18 \cdot 0\end{array}-x-5$ & $58 \cdot 4$ & $\begin{array}{l}19 \cdot 0 \\
18.5\end{array}$ & $\begin{array}{l}90 \cdot 1 \\
94.6\end{array}$ & $\begin{array}{l}17 \cdot 7 \\
10 \cdot 7\end{array}$ & $\begin{array}{l}81 \cdot 1 \\
80 \cdot 4\end{array}$ & $\begin{array}{l}16 \cdot 3 \\
11.5\end{array}$ \\
\hline $\begin{array}{l}\text { ext left } \\
\text { flex right }\end{array}$ & $\begin{array}{l}75 \cdot 1 \\
27 \cdot 5\end{array}$ & $\begin{array}{r}18.9 \\
9.5\end{array}$ & $\begin{array}{l}61.1 \\
25 \cdot 4\end{array}$ & $\begin{array}{r}18.3 \\
8.2\end{array}$ & $\begin{array}{l}94.6 \\
48 \cdot 0\end{array}$ & $12 \cdot 2$ & $\begin{array}{l}80 \cdot 4 \\
39 \cdot 2\end{array}$ & $\begin{array}{l}15 \cdot 5 \\
10 \cdot 0\end{array}$ \\
\hline $\begin{array}{l}\text { flex right } \\
\text { flex left }\end{array}$ & $38 \cdot 8$ & $12 \cdot 6$ & 32.5 & $11 \cdot 3$ & $54 \cdot 1$ & $11 \cdot 1$ & $43 \cdot 6$ & $9 \cdot 1$ \\
\hline Knee ext right $180 \% \mathrm{~s}$ & $50 \cdot 6$ & $12 \cdot 1$ & $41 \cdot 2$ & $9 \cdot 7$ & $67 \cdot 5$ & $12 \cdot 4$ & $56 \cdot 6$ & $9 \cdot 1$ \\
\hline ext left & $54 \cdot 0$ & $13 \cdot 2$ & $39 \cdot 2$ & $10 \cdot 0$ & $69 \cdot 6$ & $11 \cdot 5$ & $53 \cdot 2$ & $11 \cdot 6$ \\
\hline flex right & $21 \cdot 0$ & $8 \cdot 2$ & $14 \cdot 4$ & $8 \cdot 1$ & $40 \cdot 7$ & $12 \cdot 3$ & $29 \cdot 8$ & $9 \cdot 0$ \\
\hline flex left & $27 \cdot 2$ & $9 \cdot 4$ & $20 \cdot 3$ & $11 \cdot 1$ & $42 \cdot 4$ & $13 \cdot 0$ & $32 \cdot 9$ & $9 \cdot 8$ \\
\hline \multicolumn{9}{|l|}{ Isokinetic endurance $(\mathrm{Nm})$} \\
\hline $\begin{array}{l}\text { Knee ext right } 180 \% / s \\
\text { ext left }\end{array}$ & $\begin{array}{r}1083 \cdot 1 \\
960 \cdot 9\end{array}$ & $500 \cdot 0$ & $840 \cdot 1$ & $\begin{array}{l}474 \cdot 9 \\
410 \cdot 5\end{array}$ & $\begin{array}{l}1984.8 \\
2064.5\end{array}$ & $\begin{array}{l}354 \cdot 1 \\
374 \cdot 7\end{array}$ & $\begin{array}{l}1598.0 \\
1438.5\end{array}$ & $\begin{array}{l}308 \cdot 3 \\
464 \cdot 3\end{array}$ \\
\hline $\begin{array}{l}\text { ext left } \\
\text { flex right }\end{array}$ & $\begin{array}{l}900 \cdot 9 \\
337 \cdot 2\end{array}$ & $\begin{array}{l}562.6 \\
248.0\end{array}$ & $\begin{array}{l}781 \cdot 5 \\
232 \cdot 0\end{array}$ & $\begin{array}{l}410.5 \\
160 \cdot 3\end{array}$ & 1110.0 & $\begin{array}{l}370 \cdot 8 \\
370 \cdot 7\end{array}$ & 780.5 & $\begin{array}{l}464.3 \\
359 \cdot 4\end{array}$ \\
\hline flex left & 478.9 & $321 \cdot 0$ & $363 \cdot 0$ & $260 \cdot 4$ & $1193 \cdot 8$ & $383 \cdot 7$ & $810 \cdot 8$ & $387 \cdot 8$ \\
\hline \multicolumn{9}{|l|}{ Aerobic capacity } \\
\hline \multicolumn{9}{|l|}{$\begin{array}{l}\mathrm{Vo}_{2} \max (\mathbf{m} / \mathbf{k g} \cdot \mathbf{m i n}) \\
\mathrm{RPE}^{2}\end{array}$} \\
\hline Muscle tests & $12 \cdot 1$ & $1 \cdot 8$ & $12 \cdot 4$ & $2 \cdot 9$ & $13 \cdot 5$ & $2 \cdot 2$ & $12 \cdot 1$ & $2 \cdot 4$ \\
\hline Ergometer cycle & 13.5 & $2 \cdot 2$ & $12 \cdot 9$ & $2 \cdot 4$ & $13 \cdot 0$ & $2 \cdot 3$ & $11 \cdot 7$ & $2 \cdot 5$ \\
\hline
\end{tabular}

${ }^{*}$ ext =extensor; flex=flexor; abd=abductor; add=adductor 
Table 3 Means and standard deviations for the male patients with rheumatoid arthritis and healthy control men of the tests for isometric/isokinetic muscle strength, isokinetic endurance, aerobic capacity, and rate of perceived exertion

\begin{tabular}{|c|c|c|c|c|c|c|c|c|}
\hline \multirow[t]{2}{*}{ Test } & \multicolumn{4}{|c|}{ Men with $R A$} & \multicolumn{4}{|c|}{ Healthy control men } \\
\hline & $\begin{array}{l}(n=12) \\
\leqslant 54 \text { years } \\
\text { Mean }\end{array}$ & $S D$ & $\begin{array}{l}(n=12) \\
>54 \text { years } \\
\text { Mean }\end{array}$ & $S D$ & $\begin{array}{l}(n=16) \\
\leqslant 54 \text { years } \\
\text { Mean }\end{array}$ & $S D$ & $\begin{array}{l}(n=14) \\
>54 \text { years } \\
\text { Mean }\end{array}$ & $S D$ \\
\hline \multicolumn{9}{|l|}{ Isometric strength ( Nm) } \\
\hline $\begin{array}{l}\text { Knee ext }{ }^{*} \text { right } \\
\text { ext left } \\
\text { flex right } \\
\text { flex left } \\
\text { Hip ext right (N) } \\
\text { ext left } \\
\text { flex right } \\
\text { flex left } \\
\text { abd right } \\
\text { abd left } \\
\text { add right } \\
\text { add left }\end{array}$ & $\begin{array}{r}122 \cdot 4 \\
143 \cdot 6 \\
45 \cdot 2 \\
68 \cdot 3 \\
117 \cdot 3 \\
123 \cdot 7 \\
88 \cdot 4 \\
86 \cdot 1 \\
90 \cdot 6 \\
92 \cdot 7 \\
147 \cdot 5 \\
162 \cdot 2\end{array}$ & $\begin{array}{l}39 \cdot 6 \\
35 \cdot 9 \\
15 \cdot 0 \\
20 \cdot 3 \\
25 \cdot 6 \\
33 \cdot 2 \\
21 \cdot 8 \\
22 \cdot 8 \\
23 \cdot 9 \\
33 \cdot 0 \\
57 \cdot 4 \\
47 \cdot 8\end{array}$ & $\begin{array}{r}142 \cdot 1 \\
145 \cdot 2 \\
52 \cdot 8 \\
64 \cdot 7 \\
98 \cdot 6 \\
98 \cdot 7 \\
79 \cdot 9 \\
76 \cdot 7 \\
63 \cdot 4 \\
65 \cdot 2 \\
123 \cdot 2 \\
137 \cdot 5\end{array}$ & $\begin{array}{l}48 \cdot 8 \\
50 \cdot 9 \\
20 \cdot 3 \\
22 \cdot 0 \\
34 \cdot 9 \\
33 \cdot 1 \\
29 \cdot 8 \\
25 \cdot 2 \\
28 \cdot 0 \\
25 \cdot 2 \\
50 \cdot 8 \\
31 \cdot 0\end{array}$ & $\begin{array}{r}175 \cdot 9 \\
182 \cdot 2 \\
83 \cdot 8 \\
91 \cdot 1 \\
149 \cdot 4 \\
156 \cdot 1 \\
97 \cdot 5 \\
95 \cdot 5 \\
152 \cdot 5 \\
159 \cdot 3 \\
186 \cdot 2 \\
188 \cdot 3\end{array}$ & $\begin{array}{l}43 \cdot 3 \\
47 \cdot 7 \\
27 \cdot 9 \\
26 \cdot 0 \\
36 \cdot 6 \\
34 \cdot 8 \\
30 \cdot 7 \\
30 \cdot 6 \\
48 \cdot 2 \\
46 \cdot 8 \\
49 \cdot 8 \\
65 \cdot 2\end{array}$ & $\begin{array}{r}156 \cdot 5 \\
152 \cdot 9 \\
63 \cdot 0 \\
70 \cdot 5 \\
113 \cdot 2 \\
124 \cdot 5 \\
95 \cdot 5 \\
93 \cdot 1 \\
135 \cdot 8 \\
142 \cdot 9 \\
155 \cdot 3 \\
155 \cdot 3\end{array}$ & $\begin{array}{l}34 \cdot 4 \\
41 \cdot 1 \\
12 \cdot 3 \\
15 \cdot 6 \\
26 \cdot 6 \\
25 \cdot 4 \\
37 \cdot 4 \\
31 \cdot 1 \\
30 \cdot 6 \\
30 \cdot 7 \\
35 \cdot 9 \\
41 \cdot 5\end{array}$ \\
\hline \multicolumn{9}{|l|}{ Isokinetic strength ( $\mathrm{Nm})$} \\
\hline $\begin{array}{l}\text { Knee ext right } 60 \% \text { s } \\
\text { ext left } \\
\text { flex right } \\
\text { flex left } \\
\text { Knee ext right } 180 \% \text { s } \\
\text { ext left } \\
\text { flex right } \\
\text { flex left }\end{array}$ & $\begin{array}{r}82 \cdot 7 \\
103 \cdot 1 \\
35 \cdot 8 \\
59 \cdot 7 \\
54 \cdot 6 \\
71 \cdot 9 \\
23 \cdot 9 \\
43 \cdot 5\end{array}$ & $\begin{array}{l}47 \cdot 1 \\
35 \cdot 5 \\
16 \cdot 6 \\
23 \cdot 2 \\
29 \cdot 4 \\
26 \cdot 8 \\
12 \cdot 9 \\
22 \cdot 9\end{array}$ & $\begin{array}{r}103 \cdot 3 \\
110 \cdot 8 \\
45 \cdot 3 \\
60 \cdot 3 \\
58 \cdot 3 \\
65 \cdot 5 \\
26 \cdot 8 \\
37 \cdot 7\end{array}$ & $\begin{array}{l}26 \cdot 9 \\
36 \cdot 9 \\
20 \cdot 1 \\
22 \cdot 9 \\
18 \cdot 2 \\
20 \cdot 8 \\
14 \cdot 3 \\
12 \cdot 6\end{array}$ & $\begin{array}{r}136 \cdot 6 \\
137 \cdot 5 \\
72 \cdot 2 \\
79 \cdot 0 \\
97 \cdot 2 \\
98 \cdot 8 \\
60 \cdot 1 \\
63 \cdot 2\end{array}$ & $\begin{array}{l}32 \cdot 4 \\
39 \cdot 0 \\
17 \cdot 0 \\
18 \cdot 9 \\
21 \cdot 5 \\
23 \cdot 4 \\
18 \cdot 5 \\
17 \cdot 5\end{array}$ & $\begin{array}{r}113 \cdot 9 \\
119 \cdot 0 \\
58 \cdot 1 \\
66 \cdot 1 \\
80 \cdot 3 \\
81 \cdot 1 \\
46 \cdot 6 \\
46 \cdot 6\end{array}$ & $\begin{array}{l}21 \cdot 7 \\
23 \cdot 9 \\
13 \cdot 1 \\
16 \cdot 2 \\
15 \cdot 3 \\
16 \cdot 1 \\
14 \cdot 1 \\
14 \cdot 9\end{array}$ \\
\hline \multicolumn{9}{|l|}{ Isokinetic endurance ( $\mathrm{Nm}$ ) } \\
\hline $\begin{array}{l}\text { Knee ext right } 180 \% \text { s } \\
\text { ext left } \\
\text { flex right } \\
\text { flex left }\end{array}$ & $\begin{array}{r}1203 \cdot 7 \\
1570 \cdot 3 \\
381 \cdot 8 \\
579 \cdot 6\end{array}$ & $\begin{array}{r}933 \cdot 1 \\
1004 \cdot 6 \\
385 \cdot 0 \\
326 \cdot 9\end{array}$ & $\begin{array}{r}1420 \cdot 4 \\
1620 \cdot 4 \\
522 \cdot 6 \\
674 \cdot 3\end{array}$ & $\begin{array}{l}614 \cdot 4 \\
662 \cdot 7 \\
330 \cdot 3 \\
322 \cdot 4\end{array}$ & $\begin{array}{l}2871 \cdot 0 \\
2855 \cdot 8 \\
1669 \cdot 5 \\
1854 \cdot 1\end{array}$ & $\begin{array}{l}626 \cdot 9 \\
629 \cdot 7 \\
469 \cdot 1 \\
597 \cdot 3\end{array}$ & $\begin{array}{l}2346 \cdot 7 \\
2303 \cdot 4 \\
1319 \cdot 6 \\
1396 \cdot 5\end{array}$ & $\begin{array}{l}397 \cdot 2 \\
351 \cdot 2 \\
482 \cdot 2 \\
468 \cdot 8\end{array}$ \\
\hline $\begin{array}{l}\text { Aerobic capacity } \\
\text { Vo }_{2} \text { max }(\mathrm{ml} / \mathrm{kg} \cdot \mathrm{min}) \\
\text { RPEt }\end{array}$ & $24 \cdot 0$ & $4 \cdot 3$ & $18 \cdot 7$ & $4 \cdot 1$ & $27 \cdot 6$ & $7 \cdot 4$ & $25 \cdot 1$ & $6 \cdot 1$ \\
\hline $\begin{array}{l}\text { Muscle tests } \\
\text { Ergometer cycle }\end{array}$ & $\begin{array}{l}13 \cdot 4 \\
12 \cdot 9\end{array}$ & $\begin{array}{l}2 \cdot 6 \\
2 \cdot 9\end{array}$ & $\begin{array}{l}13 \cdot 3 \\
15 \cdot 3\end{array}$ & $\begin{array}{l}3 \cdot 3 \\
3 \cdot 2\end{array}$ & $\begin{array}{l}13 \cdot 0 \\
11 \cdot 3\end{array}$ & $\begin{array}{l}1 \cdot 5 \\
2 \cdot 8\end{array}$ & $\begin{array}{l}12 \cdot 1 \\
12 \cdot 0\end{array}$ & $\begin{array}{l}1 \cdot 4 \\
2 \cdot 2\end{array}$ \\
\hline
\end{tabular}

${ }^{*}$ ext =extensor; flex=flexor; abd=abductor; add=adductor.

TRPE $=$ rate of perceived exertion.

$(\mathrm{p}<0.05)$ and sex $(\mathrm{p}<0.0001)$ were noted, indicating that older subjects and women had reduced function.

Results for isometric strength of the hip muscle groups showed highly significant $(\mathrm{p}<0.001)$ differences for all calculations but one $(\mathrm{p}<0.05)$ - the rheumatoid group showing decreased function. In addition, there were significant age $(p<0.05)$ and sex $(p<0.0001)$ differences here, showing the same pattern as for isometric knee muscle strength (tables 2 and 3).

\section{Isokinetic muscle strength}

Highly significant differences $(p<0.0001)$ were obtained on all the measured subtests at both the velocities used (60 and 180 degrees/s-the patients with RA showing decreased function as compared with the healthy controls. In addition, a significant sex $(\mathrm{p}<0.0001)$ difference was found for the isokinetic variables of muscle strength (tables 2 and 3), indicating that muscular function was reduced more in women than in men. There were significant $(p<0.01)$ effects of age for all the variables of isokinetic muscle strength except one $(p=0.06)$, indicating that older subjects ( $>54$ years) had reduced function.

\section{Isokinetic muscular endurance}

The tests of endurance were found to discriminate (tables 2 and 3 ) between the patients with RA and the healthy controls. Highly significant differences $(p<0.0001)$ between the rheumatoid and healthy groups were found on all four subtests (extensors and flexors of the right and left legs - the patients with RA showing lower capacity than the healthy subjects. Also, there were, as expected, significant $(\mathrm{p}<0.05)$ effects relating to age $(\mathrm{p}<0.001)$ and sex $(p<0.001)$, with older subjects and women showing decreased function as compared with vounger subjects and men respectively.

\section{Rate of perceived exertion}

No significant difference was found between the rheumatoid and healthy groups for the rate of perceived exertion obtained immediately after the muscle tests. For the rate of perceived exertion obtained after the bicycle ergometer test the patients with $\mathrm{RA}$ had a significantly $(\mathrm{p}=$ $0.001)$ higher value than the healthy subjects.

\section{Aerobic capacity}

A significant difference $(\mathrm{p}<0.001)$ in aerobic capacity was found between the rheumatoid and the healthy groups, with the rheumatoid group showing decreased function. Also, a significant difference related to age $(\mathrm{p}<0.001)$ was found, indicating that older ( $>54$ years) subjects, as compared with younger ones of both groups, had decreased aerobic capacity. No significant sex difference was found here.

\section{Index of muscle function}

A significant difference $(\mathrm{p}<0.001)$ was noted between the groups for the total muscle function index, indicating that patients with RA had a poorer physical performance than healthy people. 
Sociodemographic and lifestyle variables

There was a significant $(p<0.001)$ difference in exercise habits, indicating that healthy subjects were more active than the rheumatoid patients. No significant differences in diet or smoking habits were found. Men of both groups, however, smoked more than the women $(p<0.002)$. Furthermore, there was a significant difference $(p<0.001)$ in alcohol consumption between the groups, indicating that healthy people drink alcohol more frequently than patients with RA. A significant sex difference $(p<0.006)$ was also found here, showing that men drink alcohol more often than women. Attitudes towards physical training indicated by the response to the statement 'physical training is important to me', were significantly different $(p<0.05)$ in the rheumatoid and the healthy groups. The rheumatoid patients agreed less with the statement than the healthy subjects did. Response to the statement 'physical training is fun' was not significantly different between the two groups.

\section{CORRELATIONS}

Muscle function and disease characteristics of the group with $R A$

Correlations according to Spearman were performed for the group with RA between isometric and isokinetic muscle strength, isokinetic endurance, and aerobic capacity, on the one hand, and disease duration, morning stiffness, Health Assessment Questionnaire disability index, pain, Ritchie index, joint mobility index, erythrocyte sedimentation rate, and $C$ reactive protein on the other.

Results obtained indicated that both the joint mobility index and the Health Assessment Questionnaire disability index correlated significantly with muscle strength, endurance, and aerobic capacity. There were 25 possible correlations for each of the disease characteristics mentioned. For joint mobility, 11 and 13 significant $(p<0.05)$ correlations were found for the rheumatoid women and men respectively. For the Health Assessment Questionnaire disability index the corresponding figures were 14 and $11(p<0.05)$ for women and men respectively. In addition, for the rheumatoid women only, significant correlations were found for disease duration (11 significant correlations at the $p<0.05$ level), erythrocyte sedimentation rate (18 significant correlations), $\mathrm{C}$ reactive protein (seven significant correlations), and pain (11 significant correlations). No such pattern was found for the rheumatoid men. For the Ritchie index and morning stiffness, no significant correlations were found for either women or men of the group with RA.

\section{Muscle function and lifestyle characteristics}

For both the rheumatoid and healthy groups, correlations between isometric/isokinetic muscle strength, isokinetic endurance, and aerobic capacity, on the one hand, and physical work load in daily life, motivation, exercise, diet, smoking, and alcohol habits, on the other, were assessed. Results indicated significant correlations between increased muscle strength/ endurance and heavy physical work load in daily life for the rheumatoid group (10 out of 25 significant correlation $p<0.05)$ and for the healthy subjects (four out of $25 p<0.05$ ).

\section{Discussion}

Physical capacity was found to be less in patients with RA than in healthy controls matched for age and sex. The results obtained in this study seemed to be in close agreement with the subjective experiences of muscular impairments, previously reported by patients with RA.'

A decrease in muscular strength, isometric as well as isokinetic, was expected and confirms the results of other studies. ${ }^{2-6}$ Muscular isokinetic endurance has not been studied to the same extent as muscular strength. In this study we found a highly significant decrease of isokinetic endurance of the extensors and flexors of the knee at the velocity of $\mathbf{1 8 0}$ degrees/s for the rheumatoid group as compared with the healthy group. Hsieh et al, ${ }^{6}$ however, reported no significant difference between patients with RA of mainly functional class $I$ and controls for isokinetic endurance of the knee muscle groups at the velocity of 60 degrees/s. Calculations in the latter study were based on percentage of torque decline. Thus the opposite result we obtained might have been due to different measuring procedures as well as to the study of non-comparable control groups.

Tests of endurance, performed at a velocity of 180 degrees $/ \mathrm{s}$, were found to discriminate between the two groups most clearly. This result may shed light on earlier findings-for example, the selective type II fibre (fast twich) atrophy previously reported to occur in the skeletal muscle of patients with RA of functional class II. ${ }^{20}$

Measurements of muscle strength and endurance, with an isokinetic (Cybex II) dynamometer, were chosen owing to the possibility of obtaining more exact force determinations than with manual muscle testing procedures, for example. However, the importance of correcting isokinetic measurements for the effect of gravity has previously been pointed out. ${ }^{21} 22$ In our study such corrections were made by computer. Divergent results of various isokinetic measurements might perhaps be explained, to some extent, by such methodological differences.

Muscle strength and endurance, isometric as well as isokinetic, must be related to age and sex of the subjects. ${ }^{23}$ Isokinetic muscular endurance was decreased in the group with RA compared with the healthy group. Also, women as compared with men, and older subjects ( $>54$ years) as compared with younger ones showed decreased function.

Aerobic capacity was decreased in the group with RA as compared with the healthy group, in accordance with results obtained by Ekblom et $a l^{2}$ but not with the results reported by Beals et $a .^{7}$ In the latter study, however, very sedentary matched controls were used and both patients and controls showed reduced aerobic capacity. 
Rate of perceived exertion was scored by the subjects of both groups immediately after the bicycle ergometer test. The significant difference in the rate of perceived exertion between the rheumatoid and the healthy group indicated that the patients with RA force themselves harder during the test procedure (closer to their maximum capacity) than the healthy subjects. This result was not expected as sometimes patients with RA have to 'pay' for their physical activity with increased pain or disease activity.

The finding that patients with RA were less active in daily life than healthy subjects might perhaps have been expected. In this study the rheumatoid patients also showed reduced performance on the functional tests (muscle function index). In general, patients with RA as well as rheumatologists and physiotherapists are uncertain what frequency and intensity of activity and exercise is most beneficial. Recent studies ${ }^{1024}$ show that quite intensive dynamic training can be performed by patients with RA of functional class II, with no negative side effects like increased pain or disease activity. The importance of maintaining physical activity has also been pointed out in a long term (10 years) study. ${ }^{25}$

Results obtained for both the women and men in the group with RA indicated significant correlations between muscle function, on the one hand, and joint mobility and activities of daily living (Health Assessment Questionnaire), on the other. Sufficient joint mobility is needed to perform the tests of muscle function adequately. The patients with RA included in the study had only slight limitations. Thus the results indicate that reduced joint mobility has to be observed and treated at an early stage to prevent muscular dysfunction.

In conclusion, to avoid unnecessary functional deficits for patients with RA it seems important to include and evaluate different types of muscular training in rehabilitation programmes.

We thank Professor Ulrich Moritz, head of the department of physical therapy, University of Lund, Sweden, for his valuable comments and the staff at the department of physical medicine Lund, for their kind assistance.

1 Ekdahl C, Andersson SI, Svensson B. Muscle function of the lower extremities in rheumatoid arthritis and osteoarthrosis: a descriptive study of patients in a primary health care a descriptive study of patients in a prim
district. $\mathcal{F}$ Clin Epidemiol $1989 ; 42: 947-54$.

2 Ekblom B, Lövgen O, Alderin M, Fridström M, Sätterström
G. Physical performance in patients with rheumatoid arthritis. Scand $\mathcal{F}$ Rheumatol 1974; 3: 121-5.

3 Tiselius $P$. Studies on joint temperature, joint stiffness and muscle weakness in rheumatoid arthritis: an experimental and clinical investigation. Acta Rheumatol Scand 1969; (suppl 14): 70-98.

4 Nordesjö L-O, Nordgren B, Wigren A, Kolstad K. Isometric strength and endurance in patients with severe rheumatoid arthritis or osteoarthrosis in the knee joints. Scand f Rheumatol 1983; 12: 152-6.

5 Danneskiold-Samsoe B, Grimby G. Isokinetic and isometric muscle strength in patients with rheumatoid arthritis: the relationship to clinical parameters and the influence of corticosteroid. Clin Rheumatol 1986; 5; 459-67.

6 Hsieh LF, Didenko B, Schumacher Jr R. Isokinetic and isometric testing of knee musculature in patients with rheumatoid arthritis with mild knee involvement. Arch Phys Med Rehabil 1987; 68: 294-7.

7 Beals CA, Lampman RM, Banwell BF, Braunstein EM, Albers JW, Castor CW. Measurement of exercise tolerance in patients with rheumatoid arthritis and osteoarthritis. f Rheumatol 1985; 12: 458-61.

8 Committee of the American Rheumatism Association. Diagnostic criteria for rheumatoid arthritis: 1958 revision. Ann Rheum Dis 1959; 18: 49-53.

9 Steinbrocker O, Traeger CH, Batterman RC. Therapeutic criteria in rheumatoid arthritis. $\mathcal{F} A M A$ 1949; 140: 659-62.

10 Ekdahl C, Andersson SI, Moritz U, Svensson B. Dynamic versus static training in patients with rheumatoid arthritis. versus static training in patients with
Scand f R Reumatol 1990; 19: 17-26.

11 Isolated-joint testing and exercise: $a$ handbook for using Cybex II and the U.B.X.T. TM-Cybex II. New York: Lumex, 1980: 67-70.

12 Borg GAV. Psychophysical bases of perceived exertion. Med Sci Sports Exerc 1982; 14: 377-81.

13 Åstrand I. A method for prediction of aerobic work capacity for females and males of different ages. Acta Physiol Scand 1960;49 (suppl 169): 45-60.

14 Ekdahl C, Eberhardt K, Andersson SI, Svensson B. Assessing disability in patients with rheumatoid arthritis. Use of a Swedish version of the Stanford Health Assessment Questionnaire. Scand F Rheumatol 1988; 17: 263-71.

15 Fries JF. The assessment of disability: from first to future principles. $B r \mathcal{F}$ Rheumatol 1983; 22 (suppl): 48-58.

16 Ritchie DM, Boyle JA, McInnes JM, el al. Clinical studies with an articular index for the assessment of joint tenderness in patients with rheumatoid arthritis. $Q \mathcal{F}$ Med 1968; 37: 393-406.

17 Meenan RF, Liang MH, Halder NM. Social security, disability, and the arthritic patient. Bull Rheum Dis 1983; 33: 1-7.

18 Andersson SI. Use of 'fuzzy' statements in medical decision contexts. In: van Eimeren W, Engelbrecht R, Flagle CD, eds. Third international conference on system science in health care. Berlin: Springer, 1984: 858-961.

19 SAS user's guide: Statistics. 5th edn. Cary, NC:SAS Institute Inc, 1985.

20 Edström L, Nordemar R. Differential changes in type I and type II muscle fibres in rheumatoid arthritis Scand type If muscle fibres in

21 Fillyaw M, Bevins T, Fernandez L. Importance of correcting isokinetic peak torque for the effect of gravity when calculating knee flexor to extensor muscle ratios. Phys Ther 1986; 66: 23-9.

22 Winter DA, Wells RP, Orr GW. Errors in the use of isokinetic dynamometer. Eur F Appl Physiol 1981; 46: 397-408.

23 Larsson L, Karlsson J. Isometric and dynamic endurance as a function of age and skeletal muscle characteristics. Acto Physiol Scand 1978; 104: 1-8.

24 Lyngstad K, Danneskiold-Samsoe B, Halskov O. The effect of physical training on patients with rheumatoid arthritis: changes in disease activity, muscle strength and aerobic capacity: a clinically controlled minimized cross-over study. Capacity: a clinically controlled minim

25 Million R, Poole P, Kellgren JH, Jayson MIV. Long-term study of management of rheumatoid arthritis. Lancet 1984 i: $812-6$. 